SCADidoc

International Journal of Dentistry and Oral Science (IJDOS)

ISSN: 2377-8075

\title{
Prevalence Of Dental Malocclusion And Orthodontic Treatment Needs Among Patients Visiting Private Dental College - A Retrospective Study \\ Research Article
}

Thiviya Raaj ${ }^{1}$, Arthi Balasubramaniam ${ }^{2 *}$, Sri Sakthi $\mathrm{D}^{3}$

${ }^{1}$ Saveetha Dental College and Hospitals, Saveetha Institute of Medical and Technical Sciences, Chennai - 600077 , TN, India.

${ }^{2}$ Senior Lecturer, Department of Public Health Dentistry, Saveetha Institute of Medical and Technical Sciences, Saveetha University, 162, Chennai 600077, Tamil Nadu, India.

${ }^{3}$ Reader, Department of Public Health Dentistry, Saveetha Dental College and Hospitals, Saveetha Institute of Medical and Technical Sciences (SIMATS) Saveetha University, Chennai, India.

\section{Abstract}

Prevalence of malocclusion can be studied by using indexes such as Index of Orthodontic Treatment Need (IOTN), Dental Aesthetics Index (DAI), Handicapping Labio-Lingual Deviation Index and Index of Complexity, Outcome, and Need (ICON). Dental Aesthetic Index is an orthodontic index based on socially defined aesthetic standards to determine the severity and treatment needs of malocclusion which can be used to determine the distribution of malocclusion in the study population as there is sparse reports on it while also help in orthodontic treatment planning. This study was to determine the prevalence of dental malocclusion using the dental aesthetic index (DAI). A retrospective study was conducted using case records of patients from university hospital settings. About 65 case records of patients aged above 18 years with recorded dental aesthetic index were retrieved and data was analysed using SPSS software. The results showed that out of the total study population, $72.31 \%$ of them had minor malocclusion and needed slight orthodontic treatment, $13.85 \%$ had definite malocclusion and needed elective treatment, $9.23 \%$ had severe malocclusion and needed desirable orthodontic treatment and $4.62 \%$ had handicapping malocclusion and needed mandatory orthodontic treatment. No significant association between age, gender with severity of malocclusion and orthodontic treatment needs. Within the limitations of the present study, the age group 18-25 years females had severe handicapping malocclusion and needed mandatory orthodontic treatment compared to males.

Keywords: Prevalence; Malocclusion; Dental Aesthetic Index; Orthodontic.

\section{Introduction}

Malocclusion is a problem affecting the teeth where there is misalignment or incorrect relation between teeth in the dental arches, which can be inter arch or intra arch. Most commonly seen dental malocclusion are crowding, overbite, underbite, open bite, cross bite, malocclusion of the antero-posterior plane which are Class II and III, and skeletal malocclusion. These are the most commonly occurring deviations of the teeth from the ideal occlusion. Malocclusion is usually an inherited condition but sometimes may manifest as consequences to oral habits such as thumb sucking or mouth breathing that leads to imbalance of force acting on the teeth causing malocclusion. It can be even due to trauma in a few isolated cases. Malocclusion has been identified as the third most common dental health problem, following dental caries and periodontal disease with a global prevalence that varies from 20 to 88 percent. A study conducted in Rajasthan, India reported prevalence rate of 36.42 percent and another in the state of Tamil $\mathrm{Nadu}$, India showed a prevalence rate of 15 percent $[1,2]$. In Himachal Pradesh, India, Chauhan D et al., [3] reported that 3.1\% of the children had malocclusion and in Davangere, Karnataka, $15.7 \%$ of the study population had definite malocclusion, $3.7 \%$ had severe malocclusion and $0.5 \%$ had handicapping malocclusion. Suma et al., [4] reported that urban children in Nalgonda district of Andhra Pradesh had 20.8\% prevalence rate compared to rural childrens who had prevalence rate of $14.9 \%$ [5]. A study done in Chhattisgarh, India reported that $33.2 \%$ of the participants did not have malocclusion or minor malocclusion and in

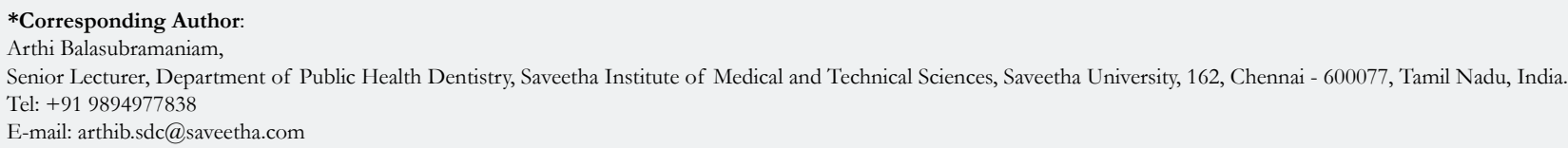

Copyright: Arthi Balasubramaniam 2021 . This is an open-access article distributed under the terms of the Creative Commons Attribution License, which permits unrestricted use, distribution and reproduction in any medium, provided the original author and source are credited. 
Maharashtra, reports observed spacing in $40.36 \%$, deep bite in $38.08 \%$, crowding in $31.88 \%$, rotation in $15.36 \%$, cross bite in $5.5 \%$ and open bite in $2.98 \%$ of school children $[6,7]$. Malocclusion is a serious health problem as the teeth are unable to perform vital functions due to the misalignment and has been proven to be a predisposing factor for several major dental problems.

Dental Aesthetics Index (DAI) is an orthodontic index based on socially defined aesthetic standards. This index was introduced by Cons et al. [8] back in 1986 to determine the severity and treatment need of malocclusion. Though many indices are available, Dental Aesthetic Index have been used in many studies [9]. An ideal index requires it to be valid and reliable, also not forgetting simple and easily applied. The dental aesthetic index was proven to fulfill all those requirements and thus, the World Health Organization (WHO) made it a cross-cultural index [10]. The dental aesthetic index scores are divided into 4 levels. They are scored based on the severity of malocclusion. The scores are; score lower than or equal to 25 which indicates no or slight treatment need, score between 26 and 30 requiring elective treatment, score between 31 and 35 indicating high need for treatment, and score greater than 36 requiring mandatory treatment [8]. Dental Aesthetic Index can be a key diagnostic index as it would aid the dentist to determine the malocclusion severity and decide if treatment is needed as it could save cost for patients with low socioeconomic status who would find a costly treatment unnecessary if it does not inhibit their daily function. Previously our team has a rich experience in working on various research projects across multiple disciplines [11-25]. This study was aimed to determine the prevalence of malocclusion and orthodontic treatment needs using the dental aesthetic index (DAI).

\section{Materials And Methods}

\section{Study Setting and Design}

A retrospective study was conducted using the records of patients visiting the author's University hospital. This study was done by reviewing 86,000 patient records of nine months from June 2019 to March 2020.

\section{Ethical Approval}

Ethical approval for this study was granted by the Institutional Review Board (IRB). The ethical ethical approval number: SDC/ SIHEC/2020/DIASDATA/0619-0320.

\section{Selection Criteria}

A total of 2167 case records diagnosed with malocclusion were sorted. Of which patients record containing information on malocclusion graded by Dental Aesthetic Index (DAI) was retrieved. About 65 patient records with age ranging from 18 years to 40 years were retrieved. No gender restriction placed. An effort was taken to remove the duplicates and incomplete records with the help of an external reviewer.

\section{Data Collection}

Information on grading of malocclusion using Dental Aesthetic Index developed by Naham C. Cons, Joanna Jenny and Frank J. Kohout in 1986 to assess orthodontic treatment needs was collected. Patients' age and gender were recorded in the separate spreadsheet. Intra oral photographs of selected subjects were assessed for cross verification. The information on DAI was recorded by the trained examiner. Age of the patients was categorized as 18-25 years, 26-32 years and 33-40 years for

\section{Statistical Analysis}

Collected data was entered in the Microsoft Excel Sheet version 8.1 and the data was imported to Statistical Package for Social Sciences (SPSS) software version 23.0. Descriptive statistics and chi-square tests were done to present the prevalence and association respectively.

\section{Results}

Most of the patients $(53.85 \%)$ included in the study were in the age group 18 -25 years, followed by $26-32$ years $(33.85 \%)$ and 33 40 years $(12.31 \%)$ shown in Figure 1 . About $67.7 \%$ of the patients were males and $33.31 \%$ were females shown in Figure 2. Among the patients $72.31 \%$ of them had minor malocclusion, $13.85 \%$ had definite malocclusion, $9.23 \%$ had severe malocclusion and $4.615 \%$ had handicapping malocclusion as shown in Figure 3. Similarly, $72.31 \%$ of them needed for slight treatment, $13.85 \%$ needed for elective treatment, $9.23 \%$ needed for desirable orthodontic treatment and $4.615 \%$ needed for mandatory orthodontic treatment as shown in Figure 4.

Among the patients, $62.86 \%, 81.82 \%$ and $87.5 \%$ of the age group 18-25 years, 26-32 years, 33-40 years had slight malocclusion. About $20 \%$ and $9.091 \%$ of patients in the age group 18-25 years and 26-32 years had definite malocclusion. Also $11.43 \%, 4.545 \%$

Figure 1: Bar chart showing distribution of age of the study participants. $X$ axis represents the age groups in years, and $Y$ axis represents the percentage of patients. Most of the study participants $(53.85 \%)$ (blue) were at the age group $18-25$ years.

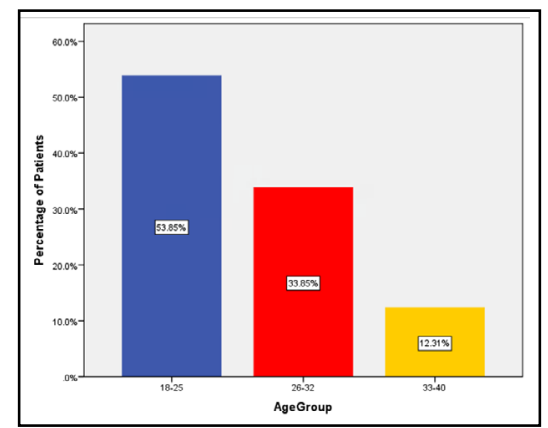


Figure 2: Bar chart showing the distribution of gender among study participants. $\mathrm{X}$ axis represents gender, and $\mathrm{Y}$ axis represents percentage of patients. Males (67.7\%) (blue) predominated the study population.

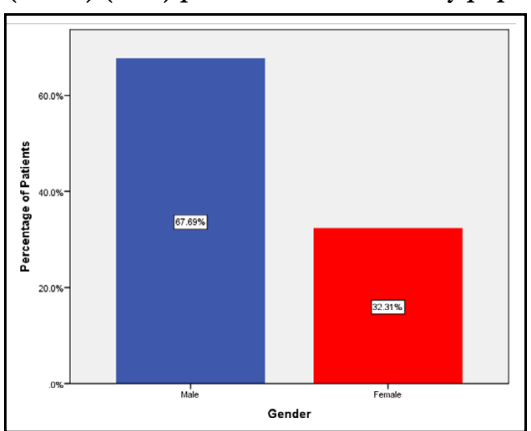

Figure 3: Bar chart showing the distribution of severity of malocclusion among the patients. $\mathrm{X}$ axis represents the scores of Dental aesthetic index, and $\mathrm{Y}$ axis represents the percentage of patients. $72.31 \%$ (blue) of the patients had a score of less than 25 of DAI, which indicates minor malocclusion, followed by $13.85 \%$ (red) with definite malocclusion, $9.23 \%$ with severe malocclusion (green) and $4.615 \%$ (yellow) with handicapping malocclusion.

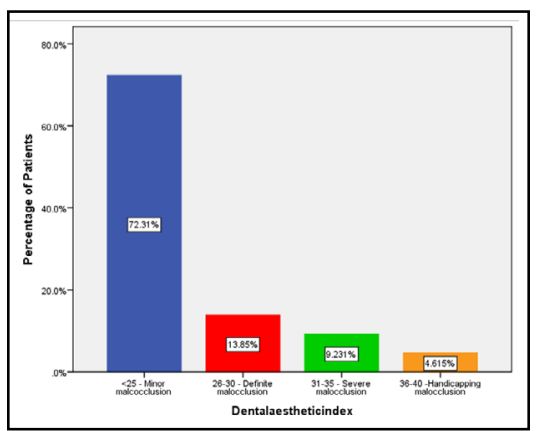

Figure 4: Bar chart showing distribution of orthodontic treatment needs among the patients. $\mathrm{X}$ axis represents the treatment needs, and $\mathrm{Y}$ axis represents the percentage of patients. About $72.31 \%$ of patients need slight orthodontic treatment (blue), followed by elective treatment (13.85\%) (red), treatment highly desirable $(9.23 \%)$ (green) and mandatory orthodontic treatment $(4.615 \%)$ (Yellow).

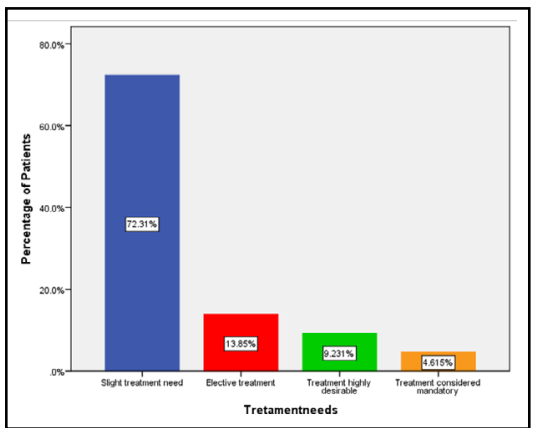

Figure 5: Cluster bar chart showing association of age and severity of malocclusion. $\mathrm{X}$ axis represents the scores of dental esthetic index (DAI) and $\mathrm{Y}$ axis represents the number of patients. Chi-square test was done and found to be statistically not significant $($ Chi-square value $=4.647 \mathrm{p}$ value $=0.590)$. Most of the patients in all groups had minor malocclusion (score $<25)$, followed by definite malocclusion (score 26-30), severe malocclusion $(31-35)$ and handicapping malocclusion $(>36)$.

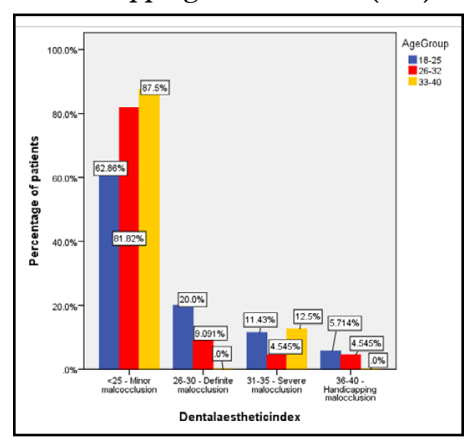

and $12.5 \%$ of patients in the age group $18-25$ years and $26-32$ years, 33-40 years had severe malocclusion respectively. About $5.714 \%$ and $5.454 \%$ of patients in the age group $18-25$ years and 26-32 years had handicapping malocclusion respectively as shown in Figure 5. In Figure 6, about 79.55\% males and 57.14\% females had minor malocclusion, $9.091 \%$ and $23.81 \%$ of male and female patients had definite malocclusion, also $9.091 \%$ and $9.524 \%$ males and females had severe malocclusion and about $2.273 \%$ and $9.524 \%$ male and female patients had handicapping malocclusion.
Among the patients, $62.86 \%, 81.82 \%$ and $87.5 \%$ of the age group 18-25 years, 26-32 years and 33-40 years needed slight orthodontic treatment. About $20 \%$ and $9.091 \%$ of patients of the age group 18-25 years and 26-32 years needed elective orthodontic treatment. Also $11.43 \%, 4.545 \%$ and $12.5 \%$ of patients in the age group 18-25 years and 26-32 years, 33-40 years needed highly desirable orthodontic treatment. About $5.714 \%$ and $5.454 \%$ of patients in the age group 18-25 years and 26-32 years needed 
Figure 6: Cluster bar chart showing association of gender with severity of malocclusion. $\mathrm{X}$ axis represents scores of dental esthetic index (DAI) and $\mathrm{Y}$ axis represents number of patients. Chi-square test was done and found to be statistically not significant $($ Chi-square value $=4.833$; $p$ value $=0.184)$. Most of the males (blue) had minor malocclusion. However, females had high prevalence of definite malocclusion and handicapping malocclusion.

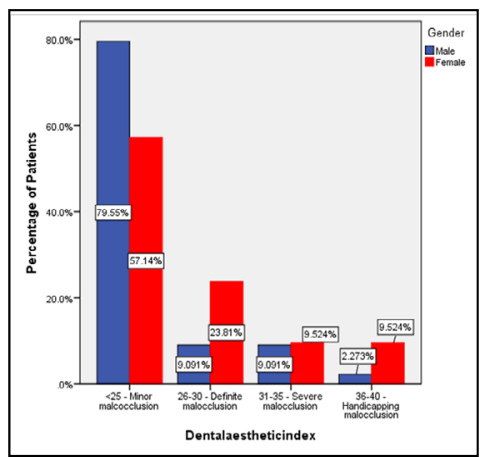

Figure 7: Cluster bar chart showing association between age and orthodontic treatment needs. $\mathrm{X}$ axis shows orthodontic treatment needs and $\mathrm{Y}$ axis shows number of patients. Chi-square test was done and found to be statistically not significant (Chi-square value $=4.647 \mathrm{p}$ value $=0.590)$. Most of the patients in all groups needed slight orthodontic treatment, followed by elective treatment, desirable orthodontic treatment and mandatory treatment. However, 3340 years not needed for elective and mandatory treatment.

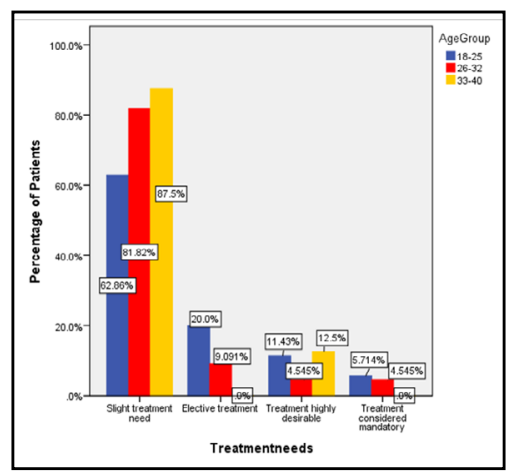

Figure 8: Cluster bar chart showing association of gender with orthodontic treatment needs. $\mathrm{X}$ axis represents orthodontic treatment needs and $\mathrm{Y}$ axis represents number of patients. Chi-square test was done and found to be statistically not significant $($ Chi-square value $=4.833$; $p$ value $=0.184)$. Most of the males (blue) needed a slight orthodontic treatment . However, females needed for elective and mandatory orthodontic treatment.

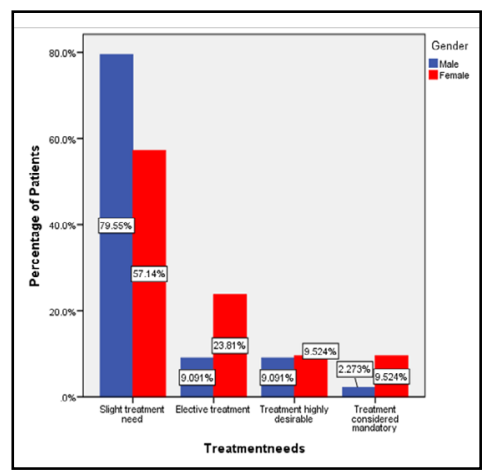

mandatory orthodontic treatment respectively as shown in Figure 7. In Figure 8, about $79.55 \%$ males and $57.14 \%$ females needed slight orthodontic treatment, $9.091 \%$ and $23.81 \%$ of male and female patients needed elective orthodontic treatment, also $9.091 \%$ and $9.524 \%$ females needed highly desirable orthodontic treatment and about $2.273 \%$ and $9.524 \%$ male and female patients needed mandatory orthodontic treatment.

\section{Discussion}

The importance of identifying these malocclusion cannot be stressed enough as they do not only have aesthetic concerns but also function and oral health. There were significant differences in gender as more males were recruited into this study compared to females; 67.7 percent. Besides that, most of the study participants $(53.85 \%)$ were between the age group of $18-25$ years old. The present study data shows that most of the patients $(72.31 \%)$ had a dental aesthetic score below 25 , followed by patients $(13.85 \%)$ with dental aesthetic scores of 26-30, and then by patients with scores of $31-35(9.23 \%)$ and above 36 (4.62\%), respectively. Chisquare test between age and the severity of malocclusion gave a value of 4.647 and was found to be statistically not significant $(p=0.590)$. Chi-square test between the variables gender and severity of malocclusion yielded a value of 4.833 and was also reported to be statistically not significant $(\mathrm{p}=0.184)$.

A supportive study reports that prevalence of some particular malocclusions may decrease or increase with time.[26] Studies are conducted on young populations because of the significance of age in context of early treatment. As most malocclusions may correct themselves or worsen with time depending on the growth pattern or environmental factors, such as early loss of deciduous teeth or trauma [27]. The reason as to why malocclusion becomes severe as age progresses has been talked about widely in the dental community, though very few studies are employed on relating an 
etiological factor that associates older age with increase in severity of malocclusion. It can be theorised that alteration in the dimensions of the jaw as age progresses may be a possible explanation as to why malocclusion becomes severe along the years. Older patients are also more prevalent to have poorer oral hygiene and this could lead to development of dental caries which leads to loss of tooth structure followed by drifting of teeth or even causing changes to the surrounding gingiva and periodontium that will eventually lead to more severe malocclusion. The prevalence of malocclusion in the study population is also less as most of the patients present with minor or no malocclusion. This is evident as the number of patients with severe and handicapping malocclusion are less than $15 \%$ of the overall population whereas patients with minor and definite malocclusion make up the majority of the study population which is above $80 \%$. This study will help to provide knowledge for better educating the people on malocclusion and the need for seeking treatment and can also enable governmental and non-governmental bodies to provide efficient dental health programmes to the mass and also helps dentist to better motivate patient to seek treatment on top of being able to procure more efficient treatment plan as it could be used as a great tool of assessment for early screening. The limitations of the study were that this was a unicentric study with geographic limitations, limited sample size and has lower external validity. Our institution is passionate about high quality evidence based research and has excelled in various fields [28-38]. The future scope of this study would be to increase the sample size by making it multicentric which could yield better results and higher correlation with varied interpretations.

\section{Conclusion}

Within the limitations of the present study, females had severe handicapping malocclusion compared to males. Also females needed mandatory orthodontic treatment compared to males. No association between age, gender with dental aesthetic score and orthodontic treatment needs. Though dental aesthetic score is an epidemiological tool, other diagnostic tools such as cephalometrics and digital model analyzer will be needed to find the severity of malocclusion and orthodontic treatment needs.

\section{References}

[1]. Dhar V, Jain A, Van Dyke TE, Kohli A. Prevalence of gingival diseases, malocclusion and fluorosis in school-going children of rural areas in Udaipur district. J Indian Soc Pedod Prev Dent. 2007 Apr-Jun;25(2):103-5.Pubmed PMID: 17660647.

[2]. Shivakumar K, Chandu G, Shafiulla M. Severity of Malocclusion and Orthodontic Treatment Needs among 12- to 15-Year-Old School Children of Davangere District, Karnataka, India. Eur J Dent. 2010 Jul;4(3):298307Pubmed. PMID: 20613919.

[3]. Chauhan D, Sachdev V, Chauhan T, Gupta KK. A study of malocclusion and orthodontic treatment needs according to dental aesthetic index among school children of a hilly state of India. J Int Soc Prev Community Dent. 2013 Jan;3(1):32-7.Pubmed PMID: 24478978.

[4]. Suma S, BR CS, Manjunath BC. Assessment of malocclusion status in relation to area of residence among 15 year old school children using Dental Aesthetic Index. Int. J. Clin. Dent.. 2011 Jun 30;3(2).

[5]. Shekar BC, Suma S, Kumar S, Sukhabogi JR, Manjunath BC. Prevalence of malocclusion among 15-year-old school children using dental aesthetic index in Nalgonda district, Andhra Pradesh, India: A cross-sectional study. J. Indian Assoc. Public Health Dent. 2014 Jul 1;12(3):173.

[6]. Shetty RM, Shetty M, Shetty NS, Reddy H, Shetty S, Agrawal A. Oral habits in children of Rajnandgaon, Chhattisgarh, India-a prevalence study. Int J Public Health Dent. 2013 Jan;4(1):1-7.

[7]. Nainani JT, Relan S. Prevalence of malocclusion in school children of nagpur rural region-an epidemiological study. JIDA. 2011;5(8):865-7.

[8]. Cons NC, Jenny J, Kohout FJ, Others. The Dental Aesthetic Index: Iowa City. A Master Thesis College of Dentistry, University of Iowa, USA. 1986.

[9]. Jenny J, Cons NC. Establishing malocclusion severity levels on the Dental Aesthetic Index (DAI) scale. Aust Dent J. 1996 Feb;41(1):43-6.Pubmed PMID: 8639114.

[10]. World Health Organization. Oral Health Surveys: Basic Methods. WHO; 1977:68

[11]. Hafeez N. Accessory foramen in the middle cranial fossa. Res J Pharm Technol. 2016;9(11):1880-2.

[12]. Krishnan RP, Ramani P, Sherlin HJ, Sukumaran G, Ramasubramanian A, Jayaraj G, et al. Surgical Specimen Handover from Operation Theater to Laboratory: A Survey. Ann Maxillofac Surg. 2018 Jul-Dec;8(2):234-238. Pubmed PMID: 30693238.

[13]. Somasundaram S, Ravi K, Rajapandian K, Gurunathan D. Fluoride Content of Bottled Drinking Water in Chennai, Tamilnadu. J Clin Diagn Res. 2015 Oct;9(10):ZC32-4.Pubmed PMID: 26557612.

[14]. Felicita AS. Orthodontic extrusion of Ellis Class VIII fracture of maxillary lateral incisor - The sling shot method. Saudi Dent J. 2018 Jul;30(3):265269.Pubmed PMID: 29942113.

[15]. Kumar S, Rahman R. Knowledge, awareness, and practices regarding biomedical waste management among undergraduate dental students. Asian J. Pharm. Clin. Res. 2017;10(8):341.

[16]. Gurunathan D, Shanmugaavel AK. Dental neglect among children in Chennai. J Indian Soc Pedod Prev Dent. 2016 Oct 1;34(4):364.

[17]. Sneha S. Knowledge and awareness regarding antibiotic prophylaxis for infective endocarditis among undergraduate dental students. Asian J. Pharm. Clin. Res. 2016 Oct 1:154-9.

[18]. Dhinesh B, Lalvani JI, Parthasarathy M, Annamalai K. An assessment on performance, emission and combustion characteristics of single cylinder diesel engine powered by Cymbopogon flexuosus biofuel. Energy Convers. Manag. 2016 Jun 1;117:466-74.

[19]. Choudhari S, Thenmozhi MS. Occurrence and Importance of Posterior Condylar Foramen. Res J Pharm Technol. 2016;9(8):11-43.

[20]. Paramasivam A, Vijayashree Priyadharsini J, Raghunandhakumar S. N6adenosine methylation $(\mathrm{m} 6 \mathrm{~A})$ : a promising new molecular target in hypertension and cardiovascular diseases. Hypertens Res. 2020 Feb;43(2):153154.Pubmed PMID: 31578458.

[21]. Wu F, Zhu J, Li G, Wang J, Veeraraghavan VP, Krishna Mohan S, et al. Biologically synthesized green gold nanoparticles from Siberian ginseng induce growth-inhibitory effect on melanoma cells (B16). Artif Cells Nanomed Biotechnol. 2019 Dec;47(1):3297-3305.Pubmed PMID: 31379212.

[22]. Palati S, Ramani P, Shrelin HJ, Sukumaran G, Ramasubramanian A, Don KR, et al. Knowledge, Attitude and practice survey on the perspective of oral lesions and dental health in geriatric patients residing in old age homes. Indian J Dent Res. 2020 Jan-Feb;31(1):22-25.Pubmed PMID: 32246676.

[23]. Saravanan M, Arokiyaraj S, Lakshmi T, Pugazhendhi A. Synthesis of silver nanoparticles from Phenerochaete chrysosporium (MTCC-787) and their antibacterial activity against human pathogenic bacteria. Microb Pathog. 2018 Apr;117:68-72.Pubmed PMID: 29427709.

[24]. Govindaraju L, Gurunathan D. Effectiveness of Chewable Tooth Brush in Children-A Prospective Clinical Study. J Clin Diagn Res. 2017 Mar;11(3):ZC31-ZC34.Pubmed PMID: 28511505.

[25]. Vijayakumar Jain S, Muthusekhar MR, Baig MF, Senthilnathan P, Loganathan S, Abdul Wahab PU, et al. Evaluation of Three-Dimensional Changes in Pharyngeal Airway Following Isolated Lefort One Osteotomy for the Correction of Vertical Maxillary Excess: A Prospective Study. J Maxillofac Oral Surg. 2019 Mar;18(1):139-146.Pubmed PMID: 30728705.

[26]. Ahangar Atashi MH. Prevalence of Malocclusion in 13-15 Year-old Adolescents in Tabriz. J Dent Res Dent Clin Dent Prospects. 2007 Spring; 1(1):13-8. Pubmed PMID: 23277828.

[27]. Akhondi MS. The prevalence of different malocclusions in the male students aged 11-13 in Sarab. JDT Dental Faculty. 2000:91-103.

[28]. Vijayashree Priyadharsini J. In silico validation of the non-antibiotic drugs acetaminophen and ibuprofen as antibacterial agents against red complex pathogens. J Periodontol. 2019 Dec;90(12):1441-1448.Pubmed PMID: 31257588.

[29]. Pc J, Marimuthu T, Devadoss P, Kumar SM. Prevalence and measurement of anterior loop of the mandibular canal using CBCT: A cross sectional study. Clin Implant Dent Relat Res. 2018 Apr 6;20(4):531-4.

[30]. Ramesh A, Varghese S, Jayakumar ND, Malaiappan S. Comparative estimation of sulfiredoxin levels between chronic periodontitis and healthy patients - A case-control study. J Periodontol. 2018 Oct;89(10):1241-1248.Pubmed PMID: 30044495

[31]. Ramadurai N, Gurunathan D, Samuel AV, Subramanian E, Rodrigues SJ. Effectiveness of $2 \%$ Articaine as an anesthetic agent in children: randomized controlled trial. Clin Oral Investig. 2019 Sep;23(9):3543-50. 
[32]. Sridharan G, Ramani P, Patankar S, Vijayaraghavan R. Evaluation of salivary metabolomics in oral leukoplakia and oral squamous cell carcinoma. J Oral Pathol Med. 2019 Apr;48(4):299-306.

[33]. Ezhilarasan D, Apoorva VS, Ashok Vardhan N. Syzygium cumini extract induced reactive oxygen species-mediated apoptosis in human oral squamous carcinoma cells. J Oral Pathol Med. 2019 Feb;48(2):115-121.Pubmed PMID: 30451321.

[34]. Mathew MG, Samuel SR, Soni AJ, Roopa KB. Evaluation of adhesion of Streptococcus mutans, plaque accumulation on zirconia and stainless steel crowns, and surrounding gingival inflammation in primary molars: randomized controlled trial. Clin Oral Investig. 2020 Sep;24(9):1-6.Pubmed PMID: 31955271

[35]. Samuel SR. Can 5-year-olds sensibly self-report the impact of developmental enamel defects on their quality of life? Int J Paediatr Dent. 2021
Mar;31(2):285-286.Pubmed PMID: 32416620.

[36]. R H, Ramani P, Ramanathan A, R JM, S G, Ramasubramanian A, et al. CYP2 C9 polymorphism among patients with oral squamous cell carcinoma and its role in altering the metabolism of benzo[a]pyrene. Oral Surg Oral Med Oral Pathol Oral Radiol. 2020 Sep;130(3):306-312.Pubmed PMID: 32773350 .

[37]. Chandrasekar R, Chandrasekhar S, Sundari KKS, Ravi P. Development and validation of a formula for objective assessment of cervical vertebral bone age. Prog Orthod. 2020 Oct 12;21(1):38.Pubmed PMID: 33043408.

[38]. Vijayashree Privadharsini J, Smiline Girija AS, Paramasivam A. In silico analysis of virulence genes in an emerging dental pathogen A. baumannii and related species. Arch Oral Biol. 2018 Oct;94:93-98.Pubmed PMID: 30015217. 